Note: This is a preprint of an abstract being submitted for publication. Contents of this paper should not be quoted nor referred to without permission of the author(s)

To be published in:

QONF. $961202--10$

Microstructure Evolution During Irradiation

Edited by T. Diaz de la Rubia, G. S. Was, I. M. Robertson, and L. W. Hobbs Materials Research Society Symposium Proceedings, 1997

\title{
Electron-Irradiation-Induced Crystallization of Amorphous Orthophosphates
}

\author{
A. Meldrum ${ }^{1}$, L. A. Boatner ${ }^{2}$, and R. C. Ewing ${ }^{1}$ \\ ${ }^{1}$ Dept. of Earth \& Planetary Sciences, University of New Mexico, Albuquerque, NM 87131, (USA) \\ ${ }^{2}$ Solid State Division, Oak Ridge National Laboratory, Oak Ridge, TN 37831-6056, (USA)
}

December 1996

\begin{abstract}
"The submitted manuscript has been authored by a contractor of the U.S. Government under contract No. DEAC05-960R22464. Accordingly, the U.S. Government retains a nonexclusive, royalty-free license to publish or reproduce the published form of this contribution, or allow others to do so, for U.S. Government purposes."
\end{abstract}

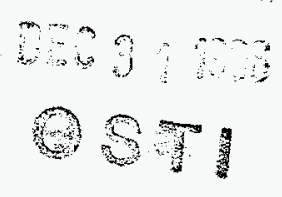

prepared by

Solid State Division

Oak Ridge National Laboratory

P.O. Box 2008

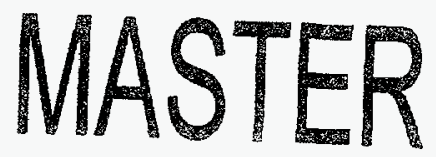

Oak Ridge, Tennessee 37831-6056

managed by

LOCKHEED MARTIN ENERGY RESEARCH CORP.

for the

U.S. DEPARTMENT OF ENERGY

under contract DE-AC05-96OR22464 


\section{DISCLAIMER}

This report was prepared as an account of work sponsored by an agency of the United States Government. Neither the United States Government nor any agency thereof, nor any of their employees, makes any warranty, express or implied, or assumes any legal liability or responsibility for the accuracy, completeness, or usefulness of any information, apparatus, product, or process disclosed, or represents that its use would not infringe privately owned rights. Reference herein to any specific commercial product, process, or service by trade name, trademark, manufacturer, or otherwise does not necessarily constitute or imply its endorsement, recommendation, or favoring by the United States Government or any agency thereor. The views and opinions of authors expressed herein do not necessarily state or reflect those of the United States Government or any agency thereof. 


\section{DISCLAMMER}

Portions of this document may be illegible in electronic image products. Images are produced from the best available original document. 


\section{ELECTRON-IRRADIATION-INDUCED CRYSTALLIZATION OF AMORPHOUS ORTHOPHOSPHATES}

A. Meldrum*, L.A. Boatner ${ }^{\dagger}$, and R.C. Ewing*

* Dept. of Earth and Planetary Sciences, University of New Mexico, Albuquerque, NM 87131-1116

† Solid State Division, Oak Ridge National Laboratory, Oak Ridge, TN 37831-6056

\section{ABSTRACT}

Amorphous $\mathrm{LaPO}_{4}, \mathrm{EuPO}_{4}, \mathrm{GdPO}_{4}, \mathrm{ScPO}_{4}, \mathrm{LuPO}_{4}$, and fluorapatite $\left[\mathrm{Ca}_{5}\left(\mathrm{PO}_{4}\right)_{3} \mathrm{~F}\right]$ were irradiated by the electron beam in a transmission electron microscope. Irradiations were performed over a range of temperatures from -150 to $300{ }^{\circ} \mathrm{C}$, electron energies from 80 to 200 $\mathrm{keV}$, and current densities from 0.3 to $16 \mathrm{~A} / \mathrm{cm}^{2}$. In all cases, the materials crystallized to form a randomly oriented polycrystalline assemblage. Crystallization is driven dominantly by inelastic processes, although ballistic collisions with the target nuclei can become important at energies higher than $175 \mathrm{keV}$, particularly in apatite. Using a high current density, crystallization is so fast that continuous lines of crystallites can be "drawn" on the amorphous matrix.

\section{INTRODUCTION}

In this study, we examine in detail the effects of 80 to $200 \mathrm{keV}$ electron irradiation on several amorphous orthophosphates of the composition $\mathrm{APO}_{4}(\mathrm{~A}=\mathrm{Sc}, \mathrm{La}, \mathrm{Eu}, \mathrm{Gd}$, or $\mathrm{Lu})$ and fluorapatite. The orthophosphates were chosen for this study for several reasons. First, in an earlier work [1], we noted that the critical amorphization dose for heavy ions in natural monazite $\left[(\mathrm{La}, \mathrm{Ce}, \mathrm{Th}) \mathrm{PO}_{4}\right]$ was significantly higher in the presence of the electron beam in the TEM, suggesting that these compounds would be good candidate materials for a study of electronirradiation-induced crystallization effects. Next, the effect of electron irradiation in the orthophosphates is considered important for a variety of technological reasons, including: a) the orthophosphates are suggested host phases for high level nuclear waste [2,3], in which a detailed understanding of radiation effects is clearly needed, b) natural orthophosphates are used extensively in uranium-lead (monazite) and uranium fission track (fluorapatite) dating, in which the age of portions of the earth's crust may be determined (e.g., [4,5]), and c) our initial work has shown that these materials may be good candidates for electron or laser lithography. Of the materials investigated here, $\mathrm{LaPO}_{4}, \mathrm{EuPO}_{4}$, and $\mathrm{GdPO}_{4}$ are isostructural, having the $P 2{ }_{1} / n, \mathrm{Z}=4$ (monazite) structure, as are $\mathrm{ScPO}_{4}$ and $\mathrm{LuPO}_{4}$, which have the closely related $I_{1} /$ amd, $\mathrm{Z}=4$ (zircon) structure. Apatite has an unrelated structure, but is similar in that it consists of a network of isolated $\mathrm{PO}_{4}$ tetrahedra interconnnected through metal-cation polyhedra.

\section{EXPERIMENTAL}

Synthetic crystals of $\mathrm{LaPO}_{4}, \mathrm{EuPO}_{4}, \mathrm{GdPO}_{4}, \mathrm{ScPO}_{4}$, and $\mathrm{LuPO}_{4}$ were grown using the flux technique [3], $\mathrm{M}_{2} \mathrm{O}_{3}(\mathrm{M}=\mathrm{Ln}, \mathrm{Sc})$ was combined with lead hydrogen phosphate and heated to $1360{ }^{\circ} \mathrm{C}$ in a platinum crucible. The system was held at this temperature for several days, cooled at $1{ }^{\circ} \mathrm{C}$ per hour to $900{ }^{\circ} \mathrm{C}$, and then quenched to room temperature. Single crystals of the orthophosphate were removed from the $\mathrm{Pb}_{2} \mathrm{P}_{2} \mathrm{O}_{7}$ flux by boiling in nitric acid for four weeks. Sample composition was subsequently checked by EDS, and X-ray diffraction analysis confirmed the monazite and zircon structure-types. 
A natural single crystal of fluorapatite from Ontario, Canada was used in this study. Polished specimens were analyzed on a JEOL 733 electron microprobe operated at an accelerating voltage of $15 \mathrm{keV}$, and the beam current was $20 \mathrm{nA}$. The beam diameter was approximately $1 \mu \mathrm{m}$. All elements were determined by wavelength-dispersive spectrometry (WDS). Data were reduced by the ZAF-4 correction technique using Oxford GENIE microprobe automation and data analysis software.

Samples were ion-milled to perforation using $4 \mathrm{keV}$ Ar ions and irradiated in the IVEM Facility at Argonne National Laboratory, which consists of a Hitachi H9000NAR electron microscope interfaced to a $400 \mathrm{keV}$ ion accelerator. Samples were irradiated by $800 \mathrm{keV} \mathrm{Kr}^{2+}$ ions at room temperature to a dose double that required for amorphization, based on the absence of electron diffraction maxima.

The samples were subsequently irradiated by an electron beam in a JEOL $2000 \mathrm{FX}$ or JEOL 2010 transmission electron microscope. The JEOL 2000FX is equipped with Gatan heating and cooling stages, each of which has a Faraday cup. All non-room-temperature experiments and all dose measurements were done on this microscope. The dose was obtained by measuring the current in the Faraday cup before and after each irradiation, and by dividing this value by the beam area. The beam area was obtained by taking a series of unobstructed photographs of the electron beam and digitally analyzing the exposed intensity. High-resolution imaging was done on the JEOL 2010, equipped with a slow scan camera. Crystallization was monitored by examining selected-area electron diffraction patterns and the corresponding bright and dark field images. The effects of electron energy were investigated by varying the accelerating voltage from 80 to $200 \mathrm{keV}$.

\section{RESULTS AND DISCUSSION}

Electron microprobe analysis of the natural apatite single crystal showed that it is a pure endmember fluorapatite, having an average chemical composition of $\mathrm{Ca}_{4.99} \mathrm{P}_{2.95} \mathrm{O}_{12} \mathrm{~F}_{1.05}$. Minor amounts of $\mathrm{Sr}, \mathrm{Na}$, and $\mathrm{Si}$ were detected, and make up the charge balance. Chemical zoning was not observed. EDS analysis of the synthetic orthophosphate crystals did not reveal any impurities. Subsequent to ion-irradiation, all the materials were checked by EDS in the TEM to account for possible ion-irradiation-induced chemical changes. For the synthetic orthophosphates, the EDS spectra before and after ion-irradiation were indistinguishable. In apatite, some fluorine + oxygen loss is evident (the fluorine and oxygen peaks suffer severe overlap). Implanted $\mathrm{Kr}$ was not detected in the EDS spectra, consistent with TRIM-96 results which indicate less than $1 \%$ implantation.

Using $200 \mathrm{keV}$ electrons at room temperature and a beam current of $1.45 \mathrm{~A} / \mathrm{cm}^{2}$, amorphous $\mathrm{LaPO}_{4}$ and $\mathrm{GdPO}_{4}$ crystallized to form a randomly oriented polycrystalline assemblage after a dose of $6.78 \times 10^{20}$ and $7.70 \times 10^{20} \mathrm{~cm}^{-2}$, respectively. The dose for EuPO 4 was indistinguishable from $\mathrm{GdPO}_{4}$, within experimental error. The first crystalline nuclei were observed after less than 60 seconds under these conditions. These nuclei grew with increasing irradiation at the same time as further nuclei formed in the still-amorphous regions. For $\mathrm{LaPO}_{4}$ and $\mathrm{GdPO}_{4}$, the result was a randomly oriented polycrystalline assemblage of crystallites having an average diameter of approximately $100 \mathrm{~nm}$ (Fig. 1).

Electron-irradiation-induced crystallization in $\mathrm{ScPO}_{4}$ and $\mathrm{LuPO}_{4}$ required an approximately $10 \mathrm{x}$ higher dose than for the monazite-structure materials. Under identical conditions as described above, $\mathrm{ScPO}_{4}$ required a dose of $9.11 \times 10^{21}$ and $\mathrm{LuPO}_{4}$ a dose of 1.38 $\times 10^{22} \mathrm{~cm}^{-2}$ to completely crystallize. The crystallites were somewhat larger in this case, with an average diameter of $150 \mathrm{~nm}$. For all the materials investigated except fluorapatite, increasing the 
current density by focusing the second condenser lens increased the crystallization time, so that letters could be continuously drawn on the amorphous matrix with a size apparently only dependent on the diameter of the electron beam (Fig. 2). Overall, the crystallization dose using $200 \mathrm{keV}$ electron irradiation increased in the order $\mathrm{LaPO}_{4}, \mathrm{GdPO}_{4}$, apatite, $\mathrm{ScPO}_{4}, \mathrm{LuPO}_{4}$.

The microstructural development of amorphous fluorapatite under electron irradiation is significantly different than for the lanthanide orthophosphates. Using $200 \mathrm{keV}$ electrons $(J=1.6$ $\mathrm{A} / \mathrm{cm}^{2}$ ), extensive bubble formation was observed. The bubbles grew up to $200 \mathrm{~nm}$ in diameter and tended to coagulate at the edge of the electron beam. The first crystalline nuclei were observed after approximately 2 minutes of irradiation. These nuclei grew epitaxially with continued irradiation, but the nucleation process slowed down and eventually stopped altogether, resulting in a few very large (up to $2 \mu \mathrm{m}$ diameter) randomly oriented crystallites (Fig. 3 ). Singlecrystal selected-area electron diffraction patterns from these crystallites unambiguously confirmed the apatite structure. In some cases, amorphous material could be identified along the grain boundaries and in the interstices between crystallites: this material did not crystallize even after prolonged irradiation. Irradiations were repeated using a beam current of $16 \mathrm{~A} / \mathrm{cm}^{2}$, initially to determine the effect of dose rate (or beam heating) on the crystallization of apatite. However, under these conditions, apatite did not crystallize; instead, cubic $\mathrm{CaO}$ precipitated out of the amorphous matrix. Extensive bubble formation occurred, as documented above under low beam current conditions. Even after prolonged irradiation, apatite could not be induced to crystallize under these conditions.

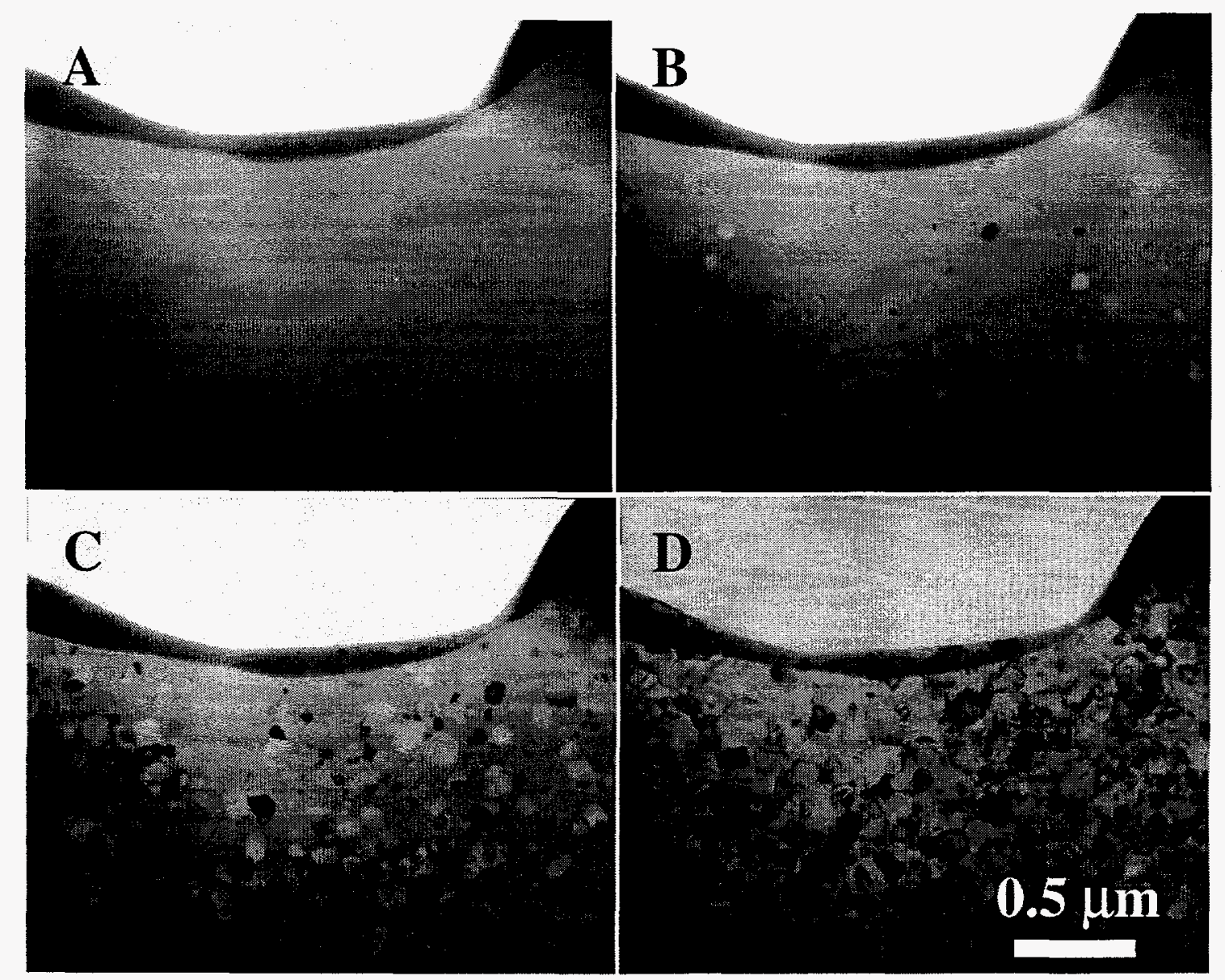

Fig. 1. Bright-field images showing an electron-beam-induced crystallization sequence in $\mathrm{LaPO}_{4}$, using a beam current density of $0.3 \mathrm{~A} / \mathrm{cm}^{2}$ : Unirradiated $(A), 1.5$ minutes $(B), 4$ minutes $(C), 6$ minutes $(D)$. 
Electron irradiations were performed over the range of -150 to $300{ }^{\circ} \mathrm{C}$, using $200 \mathrm{keV}$ electrons. In all cases, the crystallization dose decreased as temperature increased. For the $\mathrm{APO}_{4}$ orthophosphates, no change in the morphology of the crystallites as a function of temperature was observed. The incubation time for the appearance of crystalline nuclei decreased at a similar rate as the overall crystallization time. However, in apatite, electron irradiation at $16 \mathrm{~A} / \mathrm{cm}^{2}$ at $300{ }^{\circ} \mathrm{C}$ could not induce the precipitation of $\mathrm{CaO}$, in contrast to the room temperature experiments. Instead, the material crystallized to randomly oriented small $(\sim 75 \mathrm{~nm}$ average diameter) apatite crystallites (Fig. 3). Significantly less bubble formation was observed, and no remaining amorphous material was detected. Thus, in fluorapatite, the effect of temperature is to change the phase assemblage crystallized as a result of electron irradiation.

Irradiations were carried out using electron energies ranging from 80 to $200 \mathrm{keV}$ at room temperature. For all the orthophosphates, the lowest electron dose for crystallization was for the $80 \mathrm{keV}$ electrons, the lowest energy used. For the monazite- and zircon-structure

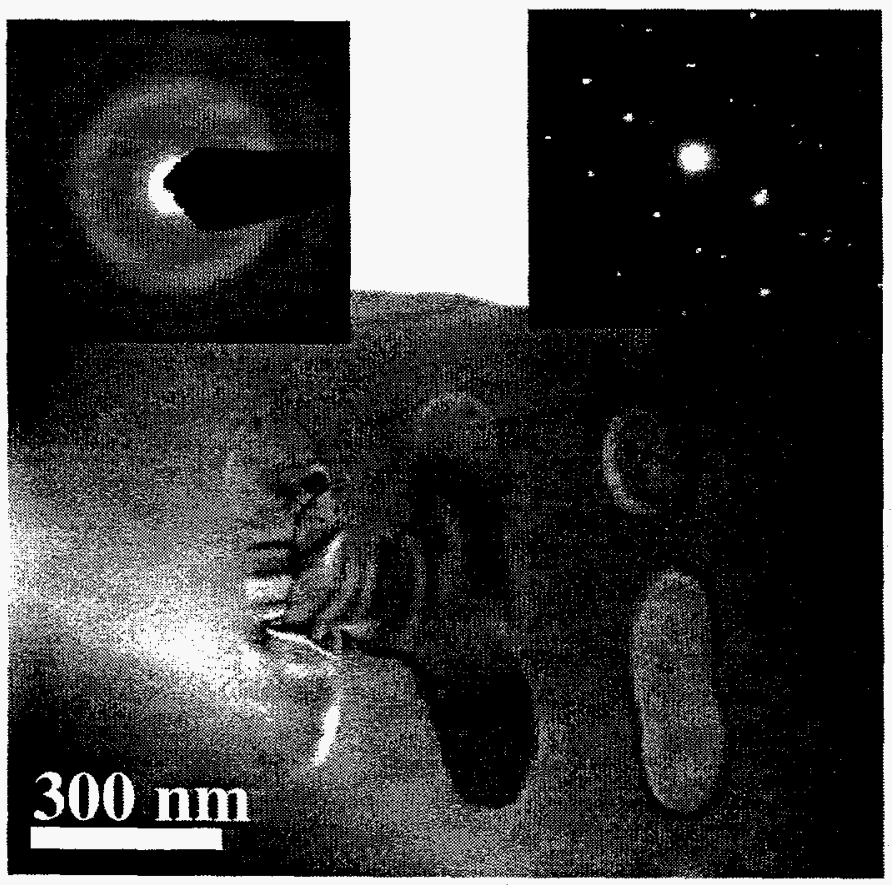

Fig. 2. Electron-irradiation-induced crystallization in $\mathrm{EuPO}_{4}$, with corresponding diffraction patterns from the amorphous matrix (top left), and from the center of the " $H$ " (top right). orthophosphates, the crystallization dose increased with increasing accelerating voltage (Fig. 4). This increase is directly proportional to the decrease in $d E / d x$ calculated from the Bethe equation. In the case of fluorapatite, the situation is different: the crystallization dose reaches a maximum at approximately $175 \mathrm{keV}$ and decreases again at $200 \mathrm{keV}$.

Any investigation of electron irradiation effects requires some discussion of the possibility that the observed microstructure evolution is due to electron beam heating, not ionization or nuclear collisions. There is no direct way of measuring sample heating from the electron beam, but Fisher's model [6] for calculating this parameter has been widely applied. According to this model, the temperature rise varies from 5 to $40{ }^{\circ} \mathrm{C}$ in these experiments. These values are considered a maximum because a) the highest measured value for the beam current was used in each case, b) the crystallization dose was independent of beam current density, within experimental error, and c) the lowest available thermal conductivities for phosphate glass was used in these calculations. Additionally, the assertion that the electron beam-induced temperature rise drives the observed phase transformations is inconsistent with the results for fluorapatite. If temperature drives the crystallization, for example, of $\mathrm{CaO}$ (focused beam conditions), then $\mathrm{CaO}$ should crystallize in the high temperature experiments (not observed).

Another possibility, other than nucleation and growth, is that electron irradiation may induce epitaxial recrystallization of relict crystallites that may be present but undetectable in the amorphous matrix after ion irradiation. For example, Miller and Ewing [7] showed that as much as $20 \%$ crystalline material in the path of the electron beam may be "invisible" in the electron microscope. However, we discard this hypothesis for the following reasons: 

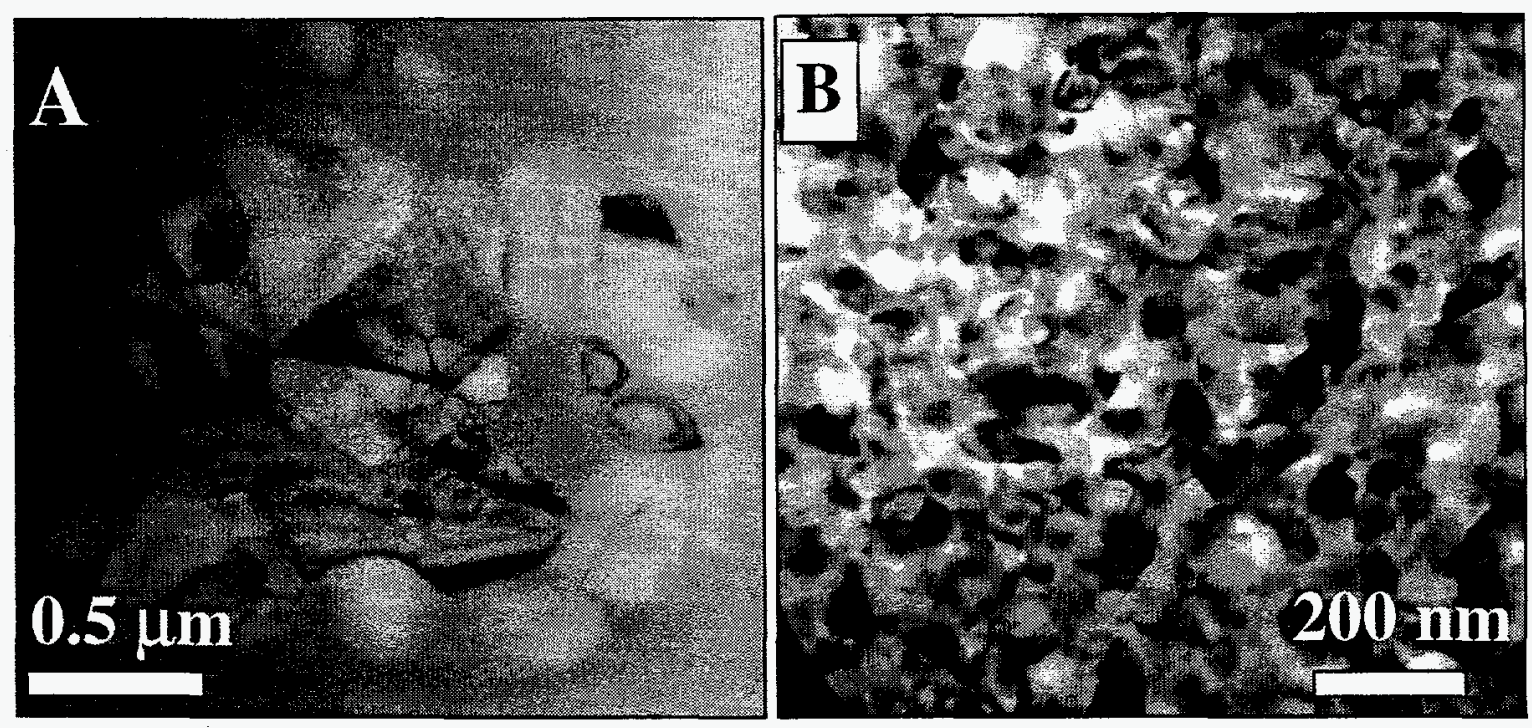

Fig. 3. Electron-irradiation-induced crystallization in fluorapatite at room temperature (A) and at $300{ }^{\circ} \mathrm{C}(B)$, using a beam current density of $1.63 \mathrm{~A} / \mathrm{cm}^{2}$. Irradiation at room temperature gives a complex assemblage of randomly oriented coarse-grained apatite crystallites, gas bubbles, and a remaining amorphous component along the grain boundaries. Irradiation at $300{ }^{\circ} \mathrm{C}(\mathrm{B})$ gives a relatively fine-grained assemblage of apatite crystallites, with only a few small gas bubbles at the grain boundaries and no observable amorphous component.

1. The materials were irradiated to a dose double that required for amorphization based on the absence of electron diffraction maxima. If $20 \%$ of the material was actually still crystalline, doubling the dose should be sufficient to amorphize the entire thickness.

2. The resulting phase assemblage is randomly oriented. Ion irradiation of single crystals can lead to the development of slightly rotated crystallite islands in an amorphous matrix; however, this rotation is invariably small.

3. The precipitation of $\mathrm{CaO}$ from amorphous apatite is not consistent with the presence of relict apatite crystals

The crystallization mechanism could be a result of defect mobility as a result of ballistic collisions with the target nuclei, bond breaking and reorganization due to ionization processes, beam heating, or a combination of these. The increase in dose with increasing beam energy documented for these materials and the strong correlation with the electronic stopping power calculated from the Bethe equation ( $r>0.95$ in all cases except apatite at energies greater than 175 $\mathrm{keV}$ ) strongly suggest that the crystallization

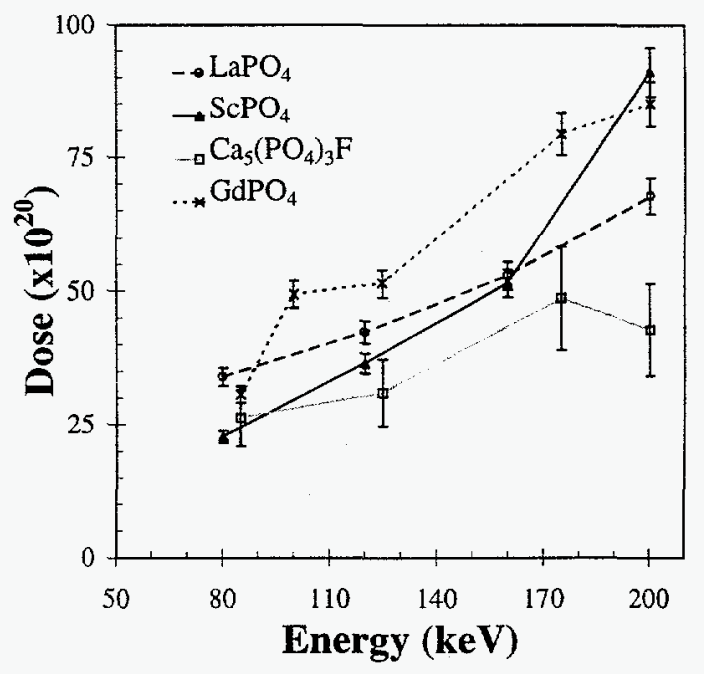

Fig. 4. Crystallization dose as a function of electron energy in the orthophosphates (only $\mathrm{LaPO}_{4}, \mathrm{GdPO}, \mathrm{ScPO}_{4}$, and apatite are shown, for clarity. The doses for $\mathrm{LaPO}_{4}$ and $\mathrm{GdPO}_{4}$ are multiplied by 10 to plot on the same axis. In all cases, the crystallization dose increases as a function of electron energy, except for the $175-200 \mathrm{keV}$ region for apatite. 
mechanism is driven dominantly by ionization processes. At high energies ballistic collisions may enhance the crystallization process, as suggested by the results for fluorapatite, in which the crystallization dose decreases above $175 \mathrm{keV}$.

The ease of crystallization in these materials is dependent on both structure and chemistry. Within the $\mathrm{APO}_{4}$ group, the monazite structure-type materials crystallized more readily than the zircon structure-type materials. Increasing the atomic number of the A-site cation had the effect of increasing the crystallization dose within each structure-type. Monazite structure-type materials have previously been shown to have a low $E_{a}$ for annealing under ionirradiation [1], attributed in part to the lower symmetry requirements, as compared with the higher symmetry zircon structure-type. These results are consistent with that view.

These results have potential application in electron lithography, as demonstrated by Fig. 2. Of all the materials investigated, amorphous $\mathrm{LaPO}_{4}$ is the most sensitive to electron irradiation. Crystallization in this material was so fast, even for a low current density, that "controlled" crystallization in the TEM was not possible. However, in the other orthophosphates the crystallization was slow enough that a focused electron beam could be used to continuously "draw" lines of crystallites by using the beam shift control knobs. Our experiments show that the size of the regions crystallized is dependent only on the diameter of the electron beam. Thus, we anticipate that nanometer-scale crystalline zones could easily be produced using a finer electron beam.

\section{CONCLUSION}

We have shown that a low energy $(80-200 \mathrm{keV})$ electron beam can be used to crystallize some ion-beam-amorphized insulating ceramics by a predominantly ionization-driven nucleation and growth process. The nucleated phase may be the same as the original unirradiated phase, as in the $\mathrm{APO}_{4}$ group, or it may be different, as in fluorapatite. The crystallization dose generally increases with increasing electron energy. Heating effects from the electron beam are not important. The rate of electron-beam-induced crystallization corresponds to the irradiationenhanced annealing activation energies and critical amorphization temperatures observed during ion-irradiation of these materials.

\section{ACKNOWLEDGMENTS}

The authors thank the staff at the HVEM-Tandem Facility at Argonne National Laboratory for their assistance with the ion irradiations. This work was supported by BES/DOE (grant \# DE-FG03-93ER45498). A.M. acknowledges financial support through a scholarship from FCAR (Québec), and from the Mineralogical Society of America.

\section{REFERENCES}

[1] A. Meldrum, L.M. Wang, and R.C. Ewing, Nuc. Inst. Meth. Phys. Res. B116, 220 (1996).

[2] L.A. Boatner, G.W. Beall, M.M. Abraham, C.B. Finch, P.G. Huray, and M. Rappaz, in Scientific Basis for Nuclear Waste Management, Vol. 2, edited by C.J.M. Northrup Jr. (Plenum, New York, 1980), p. 289.

[3] L.A. Boatner and B.C. Sales, in Radioactive Waste Forms For the Future, edited by W. Lutze and R.C. Ewing (Elsevier, Amsterdam, 1988), p. 495.

[4] L. Heaman and R.R. Parrish, in MAC Short Course on Radiogenic Isotope Systems, Vol. 19, edited by L. Heaman and J.N. Ludden (MAC, Toronto, 1991), p. 59.

[5] W.D. Carlson, Am. Min. 75, 1120 (1990).

[6] S.B. Fisher, Radiat. Eff. 5, 239 (1970).

[7] M.L. Miller and R.C. Ewing, Ultramicroscopy 48, 203 (1992). 